\title{
The Explanationist Argument For Moral Realism
}

\author{
NEIL SINCLAIR \\ University of Nottingham \\ Nottingham NG7 2RD \\ UK
}

In this paper I argue that the explanationist argument in favour of moral realism fails. According to this argument, the ability of putative moral properties to feature in good explanations provides strong evidence for, or entails, the metaphysical claims of moral realism. Some have rejected this argument by denying that moral explanations are ever good explanations. My criticism is different. I will argue that even if we accept that moral explanations are (sometimes) good explanations the metaphysical claims of realism do not follow.

\section{The Explanationist Argument}

According to moral realists, moral properties such as justice and goodness take their own unique place in nature's ontological roll-call. Although realists disagree about the nature of these moral properties - for example, whether they are reducible or otherwise constituted by non-moral or natural properties - they all agree that such properties are genuine constituents of the world that are sometimes instantiated by objects, events or states of affairs. (I discuss what 'genuine' might mean below, in §III.1.) It is these properties, realists hold, to which our moral predicates refer, whose instances are sometimes correctly represented by our moral judgements and whose distribution we can, in favourable circumstances, come to know. 
The ability of putative moral properties to feature in good explanations is one perennially attractive argument in favour of the metaphysical claims of realism. ${ }^{1}$ The initially attractive thought is that moral properties earn their ontological rights in the same way as the metaphysically unproblematic properties of the natural and social sciences, namely by figuring in good explanatory theories. ${ }^{2}$ So just as, for example, a physicist may explain why an oil droplet stays suspended in an electro-magnetic field by citing its charge, or a social scientist may explain high levels of mental illness by citing income inequality, a 'moral scientist' may explain the growth of political protest movements or social instability by citing injustice. ${ }^{3}$ Likewise, just as an observer of the physicist may explain why he believes that the oil droplet is charged by citing the charge itself, and an observer of the sociologist may explain why she believes that income inequality exists by citing the inequality itself, an observer of the 'moral scientist' may explain why they believe that a situation is unjust by citing the injustice itself. In such cases, it appears that the instantiation of a moral property - injustice - is causally relevant in producing an effect - a political protest movement or moral judgement.

The principal defender of the explanationist argument is Sturgeon. Although Sturgeon's initial interest in moral explanations was to defend against an objection to realism, he has subsequently put forward the following positive argument in favour of moral - or more broadly evaluative - realism: ${ }^{4}$

So far I have focused on the relevance of the debate about evaluative explanations to evaluative epistemology, but there appear to be implications for metaphysics too. Many evaluative explanations of non-evaluative facts look like causal explanations: decency prevents people from doing certain things; injustice, like poverty, can provoke rebellions. And it is hard to see how moral properties like

1 Henceforth, when I speak of moral realism I will be referring to just its metaphysical claims. The availability of moral explanations may also be relevant, in different ways, to the semantic, psychological, and epistemological claims of moral realism.

2 The helpful phrase 'earn ontological rights' comes from Miller (2003, 138-77), although Leiter (2001) also talks of 'ontological rights.'

3 The oil-drop example comes from Millikan (1911; 1913). For the apparent link between mental illness and income inequality see Pickett et al. (2006). The example of injustice is well-worn in the philosophical literature and receives an early statement in Brink (1989, 190-94).

4 For the original objection and reply see Harman (1977) and Sturgeon (1986). Strictly speaking, Harman's objection is only to certain non-reductive types of moral realism; elsewhere (1975) he argues that moral facts are reducible to facts about agents' motives. 
decency and injustice could have these effects unless they were real features of the world. Many philosophers also find it hard to see how they could have such effects in the natural world unless they were themselves natural properties ... . So the acceptability of these explanations, if they are acceptable, would seem to provide an argument against skeptical views that would deny the existence of such properties, and also an argument that the properties in question are natural ones. (Sturgeon 2006, 244)

Sturgeon is clear that this argument generates only a presumption in favour of realism. This is because it is based on two assumptions that may turn out to be false. First, that moral explanations are sometimes good explanations. Second, that there are no independent objections to the existence of moral properties. These assumptions are clearer in a more recent statement of the argument from Majors:

First of all, I take it as obvious that we do often say things like 'Jane gave him the money because she is a good person.' In such cases, as perhaps in others, it is perfectly natural to explain the action by reference to moral properties ... More generally any moral realist will want to acknowledge that people sometimes ... do things because they are morally right; and avoid doing others because they are morally wrong ... . I am proposing that we understand such claims precisely as we would non-moral cases. If I reach for a beer because I want to be refreshed, then my desire is the cause of my reaching. Absent some further special reason for doubting the legitimacy of such readings in the moral case, the default position ... should be to take apparent talk of moral causation at face value. (Majors 2003, 135)

Note that both Sturgeon and Majors take moral explanations to be causal explanations, that is, explanations that make a claim about the causal connections between facts or events. The most recent defence of the explanationist argument shares this feature and gives it a new twist. Jackson and Pettit (1990) have distinguished two types of causal explanation: process and programme explanations. A process explanation is one which cites a property that is directly causally efficacious in bringing about an effect, that is, a property in virtue of whose instantiation, at least in part, the effect occurs. A programme explanation is one which cites a property which, while not directly causally efficacious in bringing about the effect, programmes for (or ensures) the instantiation of some property which is directly causally efficacious in bringing about the effect. Miller (2003, 150-55) suggests that some moral explanations may be programme explanations. Although Miller ultimately rejects the claim that so treating them in anyway helps the realist position, the argument has been subsequently defended by Nelson, who summarises it as follows:

If being causally relevant is sufficient for figuring in ... best explanations, and if Miller's trial extension of programme explanation to moral properties works in the way it appeared to, and if we have no independent reasons for thinking such 
things don't exist, then Miller has shown that moral properties can earn their ontological rights. (Nelson 2006, 427-8)

How might these explanationist arguments be formalised? Here is a first attempt. ${ }^{5}$

(1) A property $\mathrm{P}$ is genuine if it figures ineliminably in a good explanation of observed phenomena.

(2) Moral properties figure ineliminably in good explanations of observed phenomena.

Therefore

(3) Moral properties are genuine.

Three points about explanationist arguments and this formalisation are worth noting. ${ }^{6}$

First, the formalisation ignores the complication, explicit in the quotes from Majors and Nelson, that the argument goes through only on the assumption that that there are no further objections to the genuineness of moral properties. Putative moral properties may feature in apparently good explanations even though they are ontologically mysterious in other ways, and this mysteriousness may prove a decisive bar to ontological respectability. In what follows I shall ignore this complication and assume that there are no further objections to the existence of moral properties. This is reasonable since I argue that the explanationist argument fails even given this assumption.

Second, it is worth highlighting the intended targets of explanationist arguments. Moral realism is opposed to two versions of moral antirealism. The first, error-theoretic version (defended in Mackie 1977 and Joyce 2001) agrees with realism that moral judgements make assertions

5 The following formulation is based loosely on those offered by Miller $(2003,140-1)$ and Nelson (2006), but differs from these in two important respects. First, it talks of properties being 'genuine' as opposed to 'real.' I explain what 'genuine' may mean below. Second, it replaces the phrase 'experience' with the phrase 'observed phenomena.' This is preferable since the former is ambiguous between the objects of experience and the experience itself. I assume the former is the intended meaning.

6 A further point worth noting is the similarity of this argument to explanatory versions of the indispensability argument for mathematical realism or 'Platonism' (see Colyvan 2001, 6-13; Baker 2005). It is an interesting question, although one I do not have space to consider here, how the criticisms offered in the current context apply to the philosophy of mathematics. 
about the distribution of moral properties — 'factualism' — but denies that there are any such properties. Consequently, according to error theorists, no (positive) moral judgements are true. The second, nonfactualist version agrees with error theory that there are no moral properties of the sort posited by realists, but denies that moral judgements attempt to state moral facts, claiming instead that they express attitudes (Blackburn 1998; Gibbard 1990) or relate part of a moral fiction (Nolan et al. 2005). It is arguable that explanationist arguments are intended as arguments against both versions of antirealism. Sturgeon, for example, presents his argument as one against views that 'deny the existence of [moral] properties,' which includes both error-theory and non-factualism. Miller and Nelson, by contrast, are primarily concerned to defend the possibility of genuine moral properties against objectors such as Harman, who argue that even if the existence of such properties was granted, they would be explanatorily redundant. Harman (1977) in effect puts forward a necessary condition on the genuineness of a class of properties and suggests that moral properties do not meet it. But it is notable that in their statements of Harman's argument, both Miller (2003, 140-41) and Nelson $(2006,417)$ include (and attribute to Harman) the corresponding sufficient condition, namely that if a property figures ineliminably in a good explanation of observed phenomenon then it is genuine. This sufficient condition need play no part in Harman's attack on realism - or in any subsequent defence - and moves the realist from a purely defensive position to a potentially offensive one. The condition is also explicitly endorsed by Majors $(2007,11)$ who suggests that 'a ... fruitful ... way for moral realists generally to approach the issue of moral explanation is to view explanatory integrity as a sufficient, though not a necessary, condition for the vindication of moral properties.' It seems then that at least some realists who defend moral explanations do so not just to bolster the ontological credentials of their posited moral properties, but also to establish those credentials from a neutral starting point. In what follows, therefore, I will assume explanationist arguments to be positive arguments in favour of realism and against all versions of antirealism. ${ }^{7}$

7 A further reason for understanding the argument in this way is the existence of structurally similar arguments in the philosophy of mathematics (see previous note). In the latter case, these arguments are intended not merely to defend the possibility of abstract mind-independent mathematical objects, but also to establish their existence (see for example, Baker 2005, 236). Even if no actual metaethicists offered the explanationist argument discussed here, therefore, it would still be worthwhile to discuss whether the explanationist argument can transfer from the mathematical to the moral case. 
Third, some brief remarks on what makes explanations 'good' are necessary. I will follow Miller (2003, 296), Sayre-McCord (1988, 272), Railton $(1998,179-84)$ and others in holding that a property features ineliminably in a good explanation just in case the unavailability of the explanation in terms of that property would lead to a genuine explanatory loss. As a definitive account of what makes explanations 'good' (or 'best') this account is obviously unsatisfactory. But it is sufficient for present purposes, since I will argue both that moral explanations are good in this sense and that this admission fails to support moral realism. My initial criticisms are therefore directed at premise (1), although modification of the argument in response to these criticisms will lead to problems elsewhere.

\section{Assessing the Argument: Moral Explanations}

The second premise of the explanationist argument is well-supported. First, by the examples already given. To be told, for example, that it is the instantiation of injustice that provoked a particular rebellion, appears a genuine explanatory gain. It tells us that the situation was unjust, and that it was these unjust conditions, rather than say, the machinations of self-interested agent provocateurs, that provoked the rebellion. To lose this explanation would seem to entail losing these pieces of information.

A stronger reason for accepting the second premise comes from the assimilation of some moral explanations to programme explanations. As Jackson and Pettit emphasise, sometimes programme explanations provide more information than any corresponding process explanation. This can happen when the programming property is multiply realizable. In such cases, the instantiation of the property programmes for one of its possible realizers but could have been realized in other ways. When it is the case that the effect would have been caused by whichever realizer was actual, an explanation in terms of the programming property captures this information. Jackson and Pettit (1990) discuss the example of temperature. Since the property of being at $100^{\circ} \mathrm{C}$, say, is a statistical property (it is property possessed by samples whose constituent molecules have a certain mean kinetic energy) it can be variously realized by various arrangements of the relevant particles with various momentum levels. When it is the case that a given effect, say the cracking of a glass container, would have been caused by any particular realization of this temperature, only the programme explanation conveys this. As Miller explains: 
A programme explanation provides a different sort of information from that which is supplied by the corresponding process account ... The process story tells us about how the history actually went: say the momentum of such and such molecules was responsible for the cracking of the glass. A programme explanation tells us about how that history might have been. It gives modal information about the history, telling us, for example that in any relevantly similar situation, as in the original situation itself, that fact that the [sample] was at $\left[100^{\circ} \mathrm{C}\right]$ means that there will be a property realized - that involving momentum of particular molecules - which is sufficient in the circumstances to produce cracking of the glass. In the actual world it was this, that and the other molecule whose momentum led to the cracking of the glass but in possible worlds where their place is taken by other molecules, the cracking still occurs. (Miller 2003, 152-53)

If some moral explanations can be assimilated to programme explanations then a similar argument would prove that those moral explanations provide information not available at any other level of description. All that is required for this to be the case is that some moral properties are multiply realizable and in a given explanation the precise realization of the moral property is irrelevant to the causal production of the effect (that is, the effect would have been caused by whichever possible realization was the actual one). This in fact appears to be the case with some explanations in terms of injustice, as Brink explains:

For example, [injustice] in [pre-1990] South Africa [consisted] in various particular social, economic and legal restrictions present in South African society. Now it seems better to cite [injustice] as a cause of political instability and social protest in [pre-1990] South Africa than the particular social, economic and political restrictions, precisely because there would have been [injustice] and instability and protest under slightly different social, economic and legal restrictions and the only thing that this large set of possible ... bases of [injustice] have in common is that they realize [injustice] ... In such cases, moral explanations will occupy a distinct and privileged role. (Brink 1989, 195) ${ }^{9}$

In other words, since some moral explanations can plausibly be assimilated to programme explanations and since programme explanations

8 Note that this is Miller's reworking of a passage from Jackson and Pettit (1990, 117). The square brackets indicate my own additions.

9 I have replaced Brink's term 'racial oppression' with 'injustice' to fit with the earlier discussion. See Majors (2003, 137-8) for a version of this argument applied to causal moral laws. One may worry that explanations such as Brink's are merely elliptical for longer explanations citing perceptions of moral features rather than the moral features themselves. However, it is doubtful that all moral explanations are elliptical in this way (for example injustice may prompt violent action even among those who have no concept of justice) and even if such elliptical explanations could always be given, so long as the moral feature was involved in the explanation of agents' perceptions of it, the moral explanation would be reinstated. 
can provide information not available at any other level of description, these moral explanations will be good explanations.

These two arguments provide strong reason to accept to second premise of the explanationist argument. For the time-being, therefore, I accept (2). (Note, however, that this premise and the arguments for it will have to be reinterpreted in light of the following criticism of the first premise).

\section{Assessing the Argument: From Moral Explanations to Moral Properties}

Not all critics of the explanationist argument rest with an attack on moral explanations. Some question whether the availability of good moral explanations - even moral programme explanations - would support realism. In this section, I outline and dismiss two arguments along these lines. I then present my own criticism of the explanationist's first premise. In light of this criticism, the explanationist argument needs to be re-interpreted and, so interpreted, it fails to establish its conclusion.

\section{Begging the question?}

Leiter has argued that premise (1) begs the question against the antirealist, here understood as someone who rejects the realists' metaphysical claims. According to a well-known criticism in the philosophy of science, due to Fine $(1984 ; 1986)$, arguments in favour of scientific realism based on inference to the best explanation beg the question against the antirealist, since one of the issues at stake in the debate between scientific realists and their opponents just is the validity of abduction. To explain, one point of disagreement between scientific realists and scientific antirealists concerns whether or not the fact that a scientific theory is explanatory provides reason think that the entities it supposedly refers to - such as electrons and their properties - are genuine existents of a theory- and mind-independent realm, a realm to which our true scientific theories correspond. According to instrumentalists such as Carnap (1959) and constructive empiricists such as van Fraassen (1980), for example, our best scientific theories (or their 'rational reconstructions') are instruments for predicting observable phenomena rather than putative representations of an unobservable theory-independent realm, and therefore do not commit the scientists who accept them to the existence of any members of this realm. It is therefore illegitimate, these anti-realists claim, to infer the mind-independent existence of unobservable entities based on a supposed commitment to 
them by our best explanatory scientific theories. Fine's argument is that given this point of contention between realists and antirealists, it is illegitimate to base an argument for one side (realism) on the very pattern of inference contested, namely inference to the best explanation. Leiter $(2001,80)$ extends the point to cover arguments in favour of any kind of realism, including moral realism. Since premise (1) captures inference to the best explanation and is part of an argument for moral realism, the resulting argument is, according to Leiter, question-begging against the moral antirealist.

There are two problems with this line of thought as a criticism of the explanationist argument for moral realism. ${ }^{10}$ The first is that Leiter's generalisation of Fine's point is unwarranted. Although the validity of abductive inference is one of the issues at stake in the debate between scientific realism and anti-realism, it is not obviously at stake in the debate between moral realism and anti-realism. The opponent of moral realism, unlike the opponent of scientific realism, is not obliged by the mere fact of this opposition to reject the validity of abductive inference. ${ }^{11}$ Rather, all the opponent of moral realism is obliged to reject are the metaphysical claims of moral realism. Therefore it is not the case that the explanationist argument for moral realism begs the question against the moral antirealist (who is the relevant opponent here).

This first response to Leiter is limited, since even accepting that the explanationist argument doesn't beg the question against the moral antirealist, it will remain unconvincing to any scientific antirealist, who will not accept (1). This is problematic for the moral realist, who may legitimately hope that the explanationist argument is not hostage to outcomes of debates in the philosophy of science. A second response avoids this problem. For (1) can be understood in a way that is acceptable even to scientific antirealists. The key lies in the term 'genuine.' If we understand 'genuine' to mean 'belonging to the sort of external, mind-independent reality posited by the scientific realist' then, for the reasons Fine gives, the premise will not be acceptable to the scientific antirealist. If, however, we understand 'genuine' in a weaker sense as meaning 'shares the same type of existence as those properties mentioned in our best scientific theories, such as charge or temperature' then even the scientific antirealist can assent to (1). For what the scientific antirealist objects to is not talk of protons, gasses or their properties,

10 To be clear, these are not criticisms of Fine's arguments against the abductive defence of scientific realism.

11 See Baker $(2005,225)$ for the same point in the context of explanatory arguments for Platonism. 
but to the further claim that our best theories of these matters correctly represent the mind-independent, objective, external world-as-it-is-initself (what Fine calls The World). So long as 'genuine' is understood in this weaker sense - the sense, for example, in which the even the antirealist can say that protons are genuine whereas phlogiston is not - then (1) is acceptable to both sides. In fact, so understood (1) is also acceptable for deflationists or nonrealists, such as Fine, who hold that the whole debate between scientific realism and antirealism is bunk, since it is based on the erroneous assumption that scientific practice as a whole requires philosophical interpretation. Such views still accept the existence of protons, gases and their properties, what they deny is the availability of any a priori debate about their metaphysical status.

Note that if 'genuine' is understood in this weaker sense, the explanationist argument for moral realism is not an argument for the conclusion that moral properties have the sort of external, mind-independent existence defended by the scientific realist, but rather an argument for thinking that moral properties have parity of ontological status with scientific properties (whatever that status may turn out to be). This would still be a significant result for the moral realist, since it would establish continuity between his postulates and those of natural science. ${ }^{12}$ To put the point another way, even without taking a stand in the debate about the metaphysical status of scientific properties (and even if there is no such debate to be had) we can consider the issue of the scientific status of moral properties. It is here that the explanationist argument for moral realism has bite. Understanding 'genuine' in the weaker sense, therefore, avoids entirely the charge of begging the question.

\section{Metaphysical arrogance?}

A more significant problem with (1) is that it seems to confer realitymaking power onto good explanations, but whether an explanation is good depends crucially on our own epistemic limitations. ${ }^{13}$ It is, this criticism urges, metaphysical arrogance to suppose that the constituents of the world are dependent on our epistemic limitations on this way. As Nelson explains:

'good explanations' can be good in two different ways: by being true or by being not-exactly-true-but-practically-useful for creatures who don't know much, have lim-

12 For the characterisation of realism as aiming for continuity between ethics and science, see Darwall et al. (1992).

13 The phrase 'reality-making power' comes from Fine $(1986,164)$. 
ited abilities to infer and predict, and are as interested in 'getting by' as 'getting it right.' If we are going to read our ontology off our explanations, then we had better read it off only the true ones, and not mere heuristic devices on a par with 'Red sky at night, sailor's delight.' (Nelson 2006, 423; following Miller 2003, 173)

The problem is that the antecedent and consequent in (1) seem to have different status: the antecedent is assessed relative to our epistemically limited position, but the consequent embodies no such restriction. The way to deal with the problem, therefore, is to aim for parity of status. There are two ways of doing this. First, we may remove the epistemic shackles from the antecedent and recognise that if there is a type of explanation that has ontological clout, it is explanation that is plausible from an epistemically unlimited position or 'God's eye view.' This is Miller's preferred route:

when we are in the business of asking which properties earn their ontological rights, we should be concerned with what properties would figure in the world as seen from a viewpoint in which all [our] epistemic limitations were transcended. $\left(\right.$ Miller 2003, 173) ${ }^{14}$

One potential problem with this view is, of course, that it is unlikely that such a premise would license any inferences for such limited beings as we are. ${ }^{15}$

An alternative is to achieve parity by placing epistemic limitations on the consequent. What follows from the fact that an explanation is best or good for those in our epistemically limited position, we might say, is that we (that is, those in that position) have some (epistemic) reason to believe in the entities that feature in it. This view avoids the charge of metaphysical arrogance by targeting as a conclusion only the claim that we have reason to believe that such-and-such property exists, a conclusion which allows for the possibility that that property might not be part of reality as seen from an epistemically unlimited point of view. ${ }^{16}$

14 In his 2009 reply to Nelson, Miller clarifies this view somewhat, suggesting that where we are interested in whether higher-level properties can earn ontological rights, we must consider whether they figure in good explanations 'considered from the point of view of a subject who suffers no epistemic limitations vis-à-vis lower-level properties and the process explanation in which they appear' (2009, 337). Note, however, that even this clarified version severely limits the number of permissible inferences that epistemically limited beings such as ourselves are able to make. (See Bloomfield 2009 for additional criticism of Miller 2009.)

15 See Sayre-McCord $(1988,268)$ for this point. See Nelson $(2006)$ for one attempt to defend such an inference.

16 Limiting the conclusion in this way is also preferable if explanatory adequacy is 
On this view, premise (1) can be replaced with (1a), and the explanationist argument runs as follows:

(1a) We have reason to believe that a property $\mathrm{P}$ is genuine if it figures ineliminably in a good explanation of observed phenomena.

(2a) Moral properties figure ineliminably in good explanations of observed phenomena.

Therefore

(3a) We have reason to believe that moral properties are genuine.

So reformulated, the explanationist argument avoids the charge of metaphysical arrogance, since reality is no longer made in the image of our good explanations (although what we have reason to believe it is). ${ }^{17}$

Note that this reformulation also accommodates the complication put aside earlier, namely that the original explanationist argument could only establish the existence of moral properties on the assumption that there is no independent reason to be sceptical of them. The reformulated argument accommodates this complication, since the conclusion is only that we have some reason to believe in the genuineness of moral properties and this is compatible with having stronger reason to believe that they are not genuine. Nevertheless, I shall continue to assume that the conclusion of the explanationist argument is not overwhelmed in this way. My criticism of the argument lies elsewhere.

\section{A category mistake}

It is tempting to think that something like (1a) explains why we have reason to believe in the existence of charge and temperature, for these properties earn their keep in good explanatory theories (such as Charles's Law). The reformulated argument, therefore, continues to capture the thought that moral properties earn their keep in the same way as those of natural and social science. But one problem remains.

Premise (1a), like (1), talks of properties 'figuring' in explanations, but such talk must be treated with caution. The Oxford English Dictionary defines an explanation as 'a statement that makes things intelligible.'

claimed to be necessary, rather than sufficient, for genuineness. This is because it is implausible to think that a property is genuine only if it is helpful in explaining what we (as limited beings) observe.

17 See Colyvan (2001, 11-12) for a structurally identical point about the conclusions of indispensability arguments. 
In their classic 1948 paper giving a taxonomy of scientific explanations, Hempel and Oppenheim take an explanation to consist of an explanandum and an explanans, where the former is the sentence describing the phenomenon to be explained' and the latter is 'the class of those sentences which are adduced to account for the phenomena' (Hempel and Oppenheim 1948, 137). In the quotation given in the previous section, Nelson gives expression to the common assumption that explanations are the sorts of things that can be true or false, and such items are commonly taken to be propositions, statements or sentences. Now, one might take a view over which of these is most properly called the 'explanation.' But this is not necessary for the current point. For understood in any of these ways explanations are linguistic or meta-linguistic items, and as such cannot literally have properties as parts, as for example a chair leg is part of a chair. This is most obvious if explanations are sentences, because sentences contain as parts linguistic items such as names and predicates, not properties. It is slightly more controversial if explanations are statements or propositions, but it is still the case that on most widely held views of these entities, they are not the sorts of things in which properties can literally figure as parts. ${ }^{18}$ Talk of properties 'figuring' in explanations is, well, figurative.

Suppose we dispense with metaphor. In any explanatory context a speaker uses an explanatory sentence (such as 'Injustice causes rebellions') to make an explanatory statement (the statement that injustice causes rebellions). Let us call the sentence the 'explanation' and say it is a good explanation just when the statement it is used to make is one the unavailability of which would lead to genuine explanatory loss. Then, we might say, it is not properties but predicates that feature in good explanations. ${ }^{19}$ Further, a predicate features ineliminably in a good explanation just in case the sentence cannot be used to make the same statement without containing that predicate. Thus we might rewrite the first premise of the explanationist argument as:

(1b) We have reason to believe that a property $\mathrm{P}$, referred to by predicate $\mathrm{S}$, is genuine if $\mathrm{S}$ figures ineliminably in a good explanation of observed phenomena.

This is the formulation sometimes preferred in the moral case by Majors, as in the following passage:

18 The exception is the Russellian view of propositions, according to which they are ordered collections of objects and properties. See Salmon and Soames (1988).

19 A closely related point applies if we take the explanations to be statements. 
If moral predicates play a role in indispensable causal explanation, then they refer to genuine, instantiated properties. (Majors 2007, 12)

In fact, however, $(1 \mathrm{~b})$ is not a good way to incorporate the point about the linguistic (or meta-linguistic) status of explanations. The problem with (1b) is that it really is question-begging against the moral antirealist. This is because of the possibility of one particular type of antirealist: the quasi-realist. This is the figure who attempts to show that while the underlying semantics of moral predicates is expressive rather than referential, the pragmatic constraints on the use of such predicates allows them to play the same sorts of roles as referential predicates. ${ }^{20}$ One such role is featuring in explanatory contexts. Of course, whether the quasirealist project can be completed in general, and in the case of moral explanations in particular, is highly controversial. But Majors' claim, and $(1 \mathrm{~b})$, preclude the very possibility of completing such a project in the case of moral explanations, since, according to these claims, any theory that can allow the functioning of moral predicates in explanatory contexts is thereby a realist theory. Consequently, both claims beg the question against quasi-realistic versions of antirealism. Sturgeon $(2006,244)$ recognises this point, since he acknowledges that antirealist accounts of moral explanations at least have to be argued against. ${ }^{21}$

A better modification of the first premise is therefore as follows:

(1c) We have reason to believe that a property $\mathrm{P}$ is genuine if a predicate $S$ figures ineliminably in a good explanation of observed phenomena and in that explanation $S$ refers to $P$.

As well as avoiding the category mistake and the charge of begging the question, this reformulation of the premise can be independently supported. A common view in the philosophy of science is that some hypotheses (statements) are justified in virtue of being involved in good explanations of observed phenomena. For example, the theory of evolution by natural selection is justified partly on the basis of its ability to explain observed physiological similarities between species. Sayre-

20 The term 'quasi-realist' was coined by Blackburn (1980, 353), although elements of the programme can be found in Hare (1952) and Stevenson (1963). It is now associated with the work of Blackburn (1993; 1998) and Gibbard (1990; 2003), among others.

21 In this respect, Majors' claim and (1b) are similar to the general view of the connection between our moral linguistic practices and realism suggested in Harcourt (2005) and criticised in Ridge (2006). 
McCord calls this the 'Explanatory Criterion,' which may be expressed as follows:

(4) We have reason to believe a hypothesis if the hypothesis plays a role in a good explanation we have of our making the observations we do. (Sayre-McCord 1988; Quinn 1986)

Such an epistemological principle tells us nothing about the ontological commitments of our best or good explanations, but it can generate such commitments when combined with a plausible application of Quine's (1953) criterion of ontological commitment, namely:

(5) We have reason to believe that a property $\mathrm{P}$ is genuine if it is quantified over by a hypothesis we have reason to believe. ${ }^{22}$

In the current context, the hypotheses in question are explanations. Further, it is plausible to assume that a property is quantified over by a hypothesis just in case the canonical statement of that hypothesis involves a predicate that refers to that property. From these assumptions, we can derive:

(1c) We have reason to believe that a property $\mathrm{P}$ is genuine if a predicate $\mathrm{S}$ figures ineliminably in a good explanation of observed phenomena and in that explanation $S$ refers to $P$.

Hence (1c) is independently plausible.

In light of the above modification to the first premise, the explanationist argument becomes:

(1c) We have reason to believe that a property $\mathrm{P}$ is genuine if a predicate $S$ figures ineliminably in a good explanation of observed phenomena and in that explanation $S$ refers to $P$.

(2c) Moral predicates feature ineliminably in good explanations of observed phenomena, and in those explanations they refer to moral properties.

Therefore

(3c) We have reason to believe that moral properties are genuine.

22 This criterion is more usually phrased in terms of the 'existence' of $\mathrm{P}$, rather than $\mathrm{P}$ being 'genuine.' The arguments of section §III.1. motivate this revision. 
This argument is, I suggest, the most plausible and literal formulation of the explanationist argument for moral realism.

\section{Criticism of the Reinterpreted Argument}

Now that the argument has been reinterpreted in the light of criticism we can consider anew whether it is compelling.

One crucial problem is that the evidence previously adduced in favour of the availability of moral explanations doesn't support premise (2c). In particular, though the arguments mentioned in §II support that linguistic claim that moral predicates figure ineliminably in good explanations, they do not support the required semantic interpretation of that claim, namely that when they so figure, they refer to moral properties. In other words, the second part of premise (2c) remains unsupported. This point deserves further explication.

Recall the arguments of $\S I$. What is the uncontroversial evidence presented by these arguments? Only the linguistic claim that moral predicates feature ineliminably in good explanations, not the semantic claim that in so doing they refer to moral properties. To see this, consider each argument in turn. The first argument was that certain moral explanations are plausible and strike us as informative. Now the realist cannot, without begging the question, provide an argument for realism that begins from the claim that moral properties exist and feature in good explanations. The suitably neutral starting point is that we use explanatory moral sentences to make explanatory moral statements and consider these statements informative. To his credit, Majors seems aware of this point: as he emphasises in the quotation given in §II, the starting point for the argument must be that we say certain things (for example that 'Jane gave him the money because she is a good person') and find them plausible. But from the fact that we employ moral sentences in explanatory contexts nothing immediately follows about how the moral predicates occurring in those sentences are understood. Nothing, in particular follows about whether or not they refer to moral properties. The linguistic phenomenon of offering and understanding moral explanations is just that: a phenomenon. To hold that those explanations involve predicates that refer to moral properties is a further act of interpretation and one that is not supported by a bare statement of the phenomenon. ${ }^{23}$

23 Majors recognises this point in a latter article, where he describes as 'paradoxical' the argument that starts from the premise that moral properties figure in causal 
Realists might reply that this point is correct but unimportant. They might argue that there is only one possible interpretation of the occurrence of moral predicates in moral explanations and that is as referring to moral properties. This, I take it, is the move Majors $(2003,135)$ endorses when he claims that 'the default position ... should be to take apparent talk of moral causation at face value.' This assumption might be justified methodologically, if there were no other interpretation of moral predication in explanatory contexts available. But, as I shall argue below, there is another interpretation available. And given this, some argument is required to choose between them. In the absence of such an argument the linguistic phenomena support neither semantic interpretation.

Before considering an alternative interpretation, consider the argument from programme explanations. According to this argument, explanations in terms of multiply realizable properties are sometimes more informative than any corresponding explanation in terms of a particular realizer. Now obviously in the present context such an argument cannot start from the premise that moral properties exist and are multiply realizable, for this begs the question against the antirealist. The proper starting point is the linguistic counterpart of this claim, namely that moral predicates are multiply satisfiable, that is, such that they can be warrantedly applied when any number of distinct (nonmoral) properties are realised. This is arguably the case with the predicate 'injustice' which, if Brink is right, can be warrantedly applied on the basis of any one of a number of political, social and economic conditions. If premise (2c) is to be supported, we must move from this uncontroversial linguistic phenomenon to a particular interpretation of it, namely that in such contexts moral predicates are being used to refer to multiply realizable properties. But, once again, what an observation about a linguistic phenomenon supports is only a conclusion about a linguistic phenomenon: in this case that because they are multiply satisfiable moral predicates can appear ineliminably in good explanations. No particular interpretation of that phenomenon follows. In particular it doesn't follow that some moral predicates are multiply satisfiable because they refer to multiply realizable properties. ${ }^{24}$ Properly under-

explanations $(2007,12)$. In response he offers the premise $(1 \mathrm{~b})$, but this, as I have argued, is equally 'paradoxical,' that is, question-begging.

24 To be fair to Brink, in Brink 1989 he is not offering an explanationist argument for moral properties, rather defending moral properties against the charge that they are explanatorily irrelevant. In that context, but not the current one, he can be justified in assuming that moral predicates refer to moral properties. Likewise, the principal concern of Nelson (2006) is to defend the explanatory relevance of moral 
stood, therefore, the argument from programme explanations supports only the first half of premise (2c). The uncontroversial evidence, we might say, is only that predicates (not properties) can programme.

Again realists might reply by suggesting that there is no alternative interpretation of the use of moral predicates in explanatory contexts to be had. In particular, they might argue, there is no way that moral predicates can be multiply satisfiable unless they refer to multiply realizable properties. If this is so, then the realist interpretation of the uncontroversial linguistic evidence may be justified in virtue of being the only available interpretation. Unfortunately this line of argument fails because there are other, nonrealist, interpretations of moral explanations available, as I shall now argue. ${ }^{25}$

\section{An Alternative Semantic Interpretation of Moral Explanations}

Just what might moral predicates be doing in the explanans of moral explanations, if not referring to moral properties? More particularly in light of the argument from programme explanations, just what might a multiply satisfiable moral predicate be doing in the explanans of a moral explanation if not referring to a multiple realisable moral property? If the answer to these question is 'Nothing' then the uncontroversial linguistic phenomenon of moral explanations also supports the referentialist interpretation, and premise (2c) is supported.

Unfortunately for realists, another interpretation is available. There are, of course, many things that we do with predicates other than refer to properties. One reasonably well-understood thing we do is express attitudes. 'Food processors are great!' exclaims the excited salesman, thereby expressing a food-processor-directed pro-attitude. According to expressivists in metaethics, moral predicates have a similar role. Might it be the case that moral predicates can figure in good causal explanations when understood expressively?

An initial problem is that such explanations must still, at base, be understood causally, that is, as picking out actual causally entwined relata. It is difficult to see how this might be if there are no moral relata

properties, although in the section quoted a more ambitious argument is clearly in view.

25 The following account is based on that given by Blackburn (1991) and Gibbard (1990). Elements of the account, in particular talk of moral standards, can be found in Hare (1952). For the realist reply that accepts the availability of alternative interpretations, but holds realism to be the most plausible, see §VI. 
to entwine. But this problem is illusory. For an explanation can feature moral predication, and pick out actual causal relata, even though neither of those relata are distinctively moral. For though, according to expressivism, the meaning of moral predicates is not to refer to moral properties, when such predicates are used they can still have the function of picking out certain instantiated non-moral properties, via the agents' idiosyncratic moral standard. To illustrate this, consider an example. David uses the term 'injustice' to express a peculiar kind of disapproval. David doesn't have this attitude in response to just any old stimulus; he has a particular moral standard. In other words, this attitude is a response to a particular kind of political, social and economic arrangement; a response to political social and economic arrangements that instantiate a certain non-moral property, call it I1. When confronted with institutions that instantiate this property David expresses his disapproval by saying 'Why, that's unjust!' Now, although the meaning of David's predicate 'unjust' is given by its propensity to express his disapproval, its use also serves, via his moral standard, to pick out the non-moral property I1. This is the non-moral property the instantiation of which satisfies David's predicate 'unjust.'

Given this expressive account, it is easy to see how moral predicates can function in explanations, even good explanations that highlight actual causally-entwined relata, without themselves referring to causally entwined relata. David utters the sentence: 'The protest movement in pre-1990 South Africa was a result of the injustices of that regime.' When he says this, we know he is expressing disapproval of the regime. We may also know, if we know his moral standard, the particular disapproval expressed is prompted by the instantiation of non-moral property I1. (We may not know David's standard, in which case we will be at a loss to know which non-moral property his use of 'unjust' picks out and will not be able to evaluate his explanation). If I1 is actually relevant to the causal production of the protest movement, then David's explanation will be a good causal explanation. Hence in answer to the question of what moral predicates might be doing in the explanans of good explanations, if not referring to moral properties, the answer is: 'Expressing attitudes that are formed in response to non-moral properties.'

What about multiple satisfiability? For some moral attitudes, David's standards may be disjunctive. In other words, the attitude is a response to a disjunctive set of non-moral properties, the instantiation of any one of which is sufficient to justify his expressive verdict. For example, the particular disapproval expressed by 'unjust' may be directed at the disjunctive set of non-moral political, social and economic properties: \{I1 or I2 or I3\}. If so, David's sincere use of the predicate 'unjust' will tell us that one of those properties has been instantiated. Now, where 
the actually instantiated property was causally productive of the relevant effect, and where it is the case that had any of the alternative realizers been instantiated they too would have been causally productive of the effect, the explanation of the effect in terms of 'injustice' will, via David's disjunctive moral standard, tell us this and hence be more informative than any explanation in terms of any particular member of the realizer set. Hence, in answer to the question of what a multiply satisfiable moral predicate might be doing in an explanation if not referring to a multiply satisfiable moral property the answer is: 'Expressing an attitude governed by a disjunctive standard.'

In light of these expressivist accounts of moral explanations, therefore, the realist cannot argue that his semantic interpretation of the linguistic data is justified by being the only available interpretation. Hence the uncontroversial linguistic data fails to support the second part of premise (2c). ${ }^{26}$

\section{An Objection Disarmed}

Realists might object that the foregoing argument proves too much. Although, they may admit, there is an alternative, non-referential, account of the use of moral predicates in explanans available, the referential interpretation of these predicates can rightly be considered a default position in the debate, that is, a position to be preferred given nothing other than the bare possibility of alternative accounts. After all, realists might argue, if referential semantics isn't, in general, the default way of understanding a set of explanatory predicates, what reason do we have for thinking that everyday explanatory predicates such as 'six foot tall' or 'round,' or scientific explanatory predicates like 'charge' or 'temperature,' refer to genuine properties? Given that we clearly do have a reason for thinking these things, it can only be because of a general presumption in favour of a referential semantics for explanatory predicates, a presumption that therefore applies in the moral context.

26 Of course, the realist may have additional arguments against the viability of expressivism, which are ipso facto arguments against expressivist accounts of moral explanations, reinstalling some support for the second part of (2c). (The objections to the explanationist argument offered by Leiter and Miller do not share this particular vulnerability.) However, in that case, the explanationist argument would be redundant as an argument against expressivism, and could not function as an argument against any form of antirealism in isolation from the additional arguments against expressivism. To paraphrase the realist, the explanationist argument would no longer pull its own weight. (Thanks to two anonymous referees for this point.) 
Unfortunately, this argument doesn't support the existence of a presumption in the moral case. In the case of everyday explanatory predicates, we might have a reason for preferring referential semantics, but if so it is most likely that there is no alternative semantics of those predicates available, in explanatory contexts or elsewhere. ${ }^{27}$ This reason obviously doesn't transfer to the moral case, where alternative semantic theories are available, theories that, as explained in $\S \mathrm{V}$, can apply in explanatory contexts. In the case of scientific explanatory predicates, at least in the case of theoretical terms, it is not clear that we do have a reason for preferring referential semantics. In so far as the anti-realist accounts of science, such as van Fraassen's, are successful they throw doubt on the claim that theoretical terms like 'charge' make reference to mind-independent, unobservable properties. Of course, problems with scientific antirealism may provide reason to prefer the referential semantics of these terms offered by scientific realists, but if so, this reason applies only in the case of theoretical terms, and will not transfer to the moral case. Hence the treatment of everyday and scientific explanatory predicates fails to support the presumption in the moral case. In that case, we are left with (at least) two competing interpretations of the semantics of moral explanations, each adequate to the linguistic evidence so far presented, yet carrying different metaphysical commitments.

I can think of only two ways to avoid this impasse. First, realists might seek to provide a more detailed analysis of the linguistic (and meta-linguistic) evidence provided by our practices of offering and understanding moral explanations and argue that some particular feature of these practices, so far unremarked, bears only a realist interpretation. For example, realists might argue that there are some moral explanations offered by agents who are completely indifferent to the moral predicates deployed; if so, it is hard to see how these predicates could be functioning to express pro-attitudes. Alternatively, moral realists may provide independent reasons for thinking moral predicates refer to genuinely instantiated properties, in explanatory contexts and elsewhere. In that case, however, the explanationist argument will no longer provide independent support for realism, even of a presumptive kind.

27 Or, if there are (plausible) semantic alternatives in the case of everyday predicates, there is no reason to prefer referential semantics in that case and hence no presumption that transfers to the moral case. 


\section{Conclusion}

The explanationist argument in favour of the existence of moral properties is multiply presumptive. That is to say, the argument is only successful granted the truth of certain assumptions. The first is that some moral explanations are good explanations. The second is that there are no independently weighty reasons to doubt the existence of moral properties. I have granted these assumptions and argued that the argument is presumptive in another way: it succeeds only granting that when moral predicates feature in good explanations, they are referring to instantiated moral properties. I have argued that the non-question begging linguistic evidence in this case (principally, the fact we offer moral explanations and find them plausible) doesn't support this assumption. Nor is it supported on the basis that it provides the only possible interpretation of moral predication in explanatory contexts because at least one other interpretation is available. The conclusion is that the explanationist argument for moral realism is unsuccessful as it stands. Moral realists have failed to bridge the gap between the explanatory indispensability of moral predicates and the explanatory indispensability of moral properties.

One notable consequence of this argument is an illumination of some previously ignored logical space in the debate concerning moral realism and explanation. Previously three positions were well-understood and represented (see, for example, Majors 2003, 121). First, the position of accepting both realism and the availability of good moral explanations. Second, accepting realism but denying the availability of good moral explanations. Third, denying both realism and the availability of good moral explanations. If the above argument is correct, a fourth position should prove equally habitable: denying moral realism whilst maintaining the availability of good moral explanations.

Received: October 2009

Revised: May 2010 


\section{References}

Blackburn, S. 1980. 'Truth, Realism and the Regulation of Theory.' Midwest Studies in Philosophy 5: 353-71.

1991. 'Just Causes.' Philosophical Studies 61: 3-17.

1993. Essays in Quasi-Realism. Oxford: Oxford University Press.

1998. Ruling Passions. Oxford: Clarendon Press.

Baker, A. 2005. 'Are there Genuine Mathematical Explanations of Physical Phenomena?' Mind 114: 223-38.

Bloomfield, P. 2009. 'Moral Realism and Programme Explanation: A Very Short Symposium 1: Reply to Miller.' Australasian Journal of Philosophy 87: 343-4.

Carnap, R. 1959. 'The Elimination of Metaphysics Through Logical Analysis of Language.' In Logical Positivism, A.J. Ayer, ed. New York: Free Press.

Colyvan, M. 2001. The Indispensability of Mathematics. Oxford: Oxford University Press.

Darwall, S., Gibbard, A., and Railton, P. 1992. 'Toward Fin de siècle Ethics: Some Trends.' Philosophical Review 101: 115-89.

Fine, A. 1984. 'The Natural Ontological Attitude.' In Scientific Realism, J. Leplin, ed. Berkeley: University of California Press.

. 1986. 'Unnatural Attitudes: Realist and Instrumentalist Attachments to Science.' Mind 95: 149-79.

Gibbard, A. 1990. Wise Choices, Apt Feelings: A Theory of Normative Judgement. Oxford: Oxford University Press.

2003. Thinking How to Live. Cambridge, MA: Harvard University Press.

Harcourt, E. 2005. 'Quasi-Realism and Ethical Appearances.' Mind 114: 249-75.

Hare, R.M. 1952. The Language of Morals. Oxford: Oxford University Press.

Harman, G. 1975. 'Moral Relativism Defended.' Philosophical Review 84: 3-22. 1977. The Nature of Morality. Oxford: Oxford University Press.

Hempel, C.G. and P. Oppenheim. 1948. 'Studies in the Logic of Explanation.' Philosophy of Science 15: 135-75.

Jackson, F. and P. Pettit. 1990. 'Program Explanation: A General Perspective.' Analysis 50: $107-17$.

Joyce, R. 2001. The Myth of Morality. Cambridge: Cambridge University Press.

Leiter, B. 2001. 'Moral Facts and Best Explanations.' Social Philosophy and Policy 18: 79-101.

Mackie, J.L. 1977. Ethics: Inventing Right and Wrong. London: Penguin.

Majors, B. 2003. 'Moral Explanation and the Special Sciences.' Philosophical Studies 113: $121-52$.

2007. 'Moral Explanation.' Philosophy Compass 2: 1-15.

Miller, A. 2003. An Introduction to Contemporary Metaethics. Cambridge: Polity Press. 
2009. 'Moral Realism and Programme Explanation: A Very Short Symposium 1: Reply to Nelson.' Australasian Journal of Philosophy 87: 337-41.

Millikan, R.A. 1911. 'The Isolation of an Ion, A Precision Measurement of its Charge, and the Correction of Stoke's Law.' Physical Review (Series 1) 32: 349-97.

. 1913. 'On the Elementary Electrical Charge and the Avogadro Constant.' Physical Review (Series II) 2: 109-43.

Nolan, D., G. Restall, \& C. West. 2005. 'Moral Fictionalism Versus the Rest.' Australasian Journal of Philosophy 83: 307-30.

Nelson, M. 2006. 'Moral Realism and Programme Explanation.' Australasian Journal of Philosophy 84: 417-28.

Pickett, K.E., O.W. James, \& R.G.. Wilkinson. 2006. 'Income Inequality and the Prevalence of Mental Illness: A Preliminary International Analysis.' Journal of Epidemiology and Community Health 60: 646-7.

Quine, W. 1953. From a Logical Point of View. Cambridge, MA: Harvard University Press.

Quinn, W. 1986. 'Truth and Explanation in Ethics.' Ethics 96: 524-44.

Railton, P. 1998. 'Moral Explanation and Moral Objectivity.' Philosophy and Phenomenological Research 58: 175-82.

Ridge, M. 2006. 'Saving the Ethical Appearances.' Mind 115: 633-50.

Sayre-McCord, G. 1988. 'Moral Theory and Explanatory Impotence.' In Essays on Moral Realism, G. Sayre-McCord, ed. Ithaca, NY: Cornell University Press.

Salmon, N. and S. Soames, eds. 1988. Propositions and Attitudes. Oxford: Oxford University Press.

Stevenson, C.L. 1963. Facts and Values: Studies in Ethical Analysis. New Haven and London: Yale University Press.

Sturgeon, N. 1986. 'Harman on Moral Explanations of Natural Facts.' Southern Journal of Philosophy 24, supplement: 69-78.

1988. 'Moral Explanations.' In Essays on Moral Realism, G. Sayre-McCord, ed. Ithaca, NY: Cornell University Press.

. 2006. 'Moral Explanations Defended.' In Contemporary Debates in Moral Theory, J. Dreier, ed. Oxford: Blackwell.

van Fraassen, B., 1980. The Scientific Image. Oxford: Oxford University Press. 